Sādhanā Vol. 38, Part 3, June 2013, pp. 447-459. (c) Indian Academy of Sciences

\title{
Post-buckling analysis of composite beams: A simple intuitive formulation
}

\author{
JAGADISH BABU GUNDA ${ }^{\mathrm{a}, *}$ and G VENKATESWARA RAO ${ }^{\mathrm{b}}$ \\ ${ }^{a}$ Advanced Systems Laboratory, Kanchanbagh, Hyderabad 500058, India \\ ${ }^{b}$ Vardhman College of Engineering, Shamshabadh, Hyderabad 501218, India \\ e-mail: jagadishasl@gmail.com
}

MS received 31 December 2011; accepted 10 April 2013

\begin{abstract}
Post-buckling analysis of composite beams with axially immovable ends is investigated using an Intuitive formulation. Intuitive formulation uses two parameters namely critical buckling load and axial stretching force developed in the post-buckled domain of composite beam. Geometric nonlinearity of von-Karman type is taken into consideration which accounts for membrane stretching action of the beam. Axial stretching force developed in post-buckled domain of composite beam is evaluated by using an axial governing equation and is expressed either in terms of lateral displacement function as an integrated value, or as a function of both axial and lateral displacement functions at any discrete location of the beam. The available expressions of critical buckling load and derived expressions of axial stretching force developed in the beam are used for obtaining an approximate closed-form expressions for the post-buckling loads of various beam boundary conditions. Numerical accuracy of the proposed analytical closed-form expressions obtained from the intuitive formulation are compared to the available finite element solutions for symmetric and asymmetric lay-up schemes of laminated composite beam. Effect of central amplitude ratio and lay-up orientation on post-buckling load variation is briefly discussed for various beam boundary conditions considered in this study.
\end{abstract}

Keywords. Post-buckling; intuitive formulation; composite beams; von-Karman type of nonlinearity; lay-up orientation.

\section{Introduction}

The use of composite materials in optimized aerospace structures requires to operate in the postbuckled domain in order to utilize its structural strength to near optimum capacity. Post-buckling (thermal or mechanical) analysis of general structural members such as beams and plates (Carlos 2009; Emam 2011; Emam \& Nayfeh 2009, 2010; Gunda et al 2011; Gupta et al 2009, 2010a, b; Huang \& Han 2009; Iyengar 1988; Jones 2006; Li \& Zhou 2005; Nayfeh \& Emam 2008;

*For correspondence 


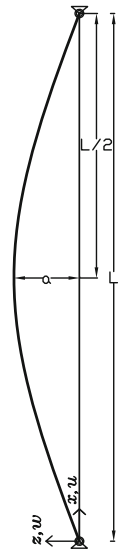

(a) $\mathrm{H}-\mathrm{H}$

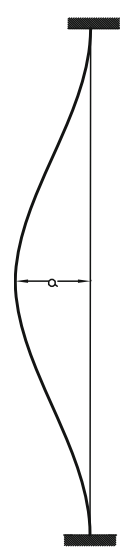

(b) C-C

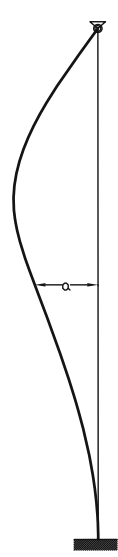

(c) $\mathrm{C}-\mathrm{H}$

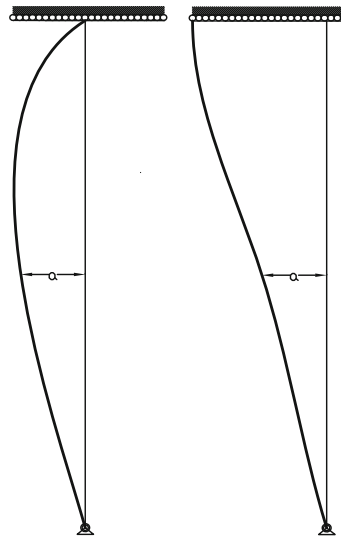

(d) H-G1

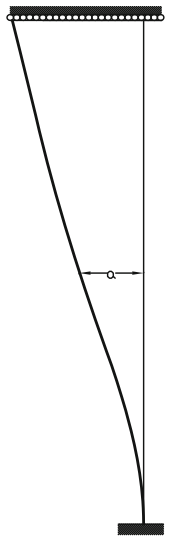

(f) C-G1

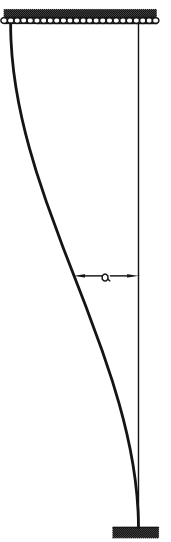

(g) C-G2

Figure 1. Beams with different boundary conditions.

Niels \& Alexander 2008; Razakamiadana \& Zidi 1999; Reddy 2003, 2004; Sebastian 2008; Vaz \& Patel 2007; Venkateswara Rao \& Raju 1984, 2002) has been studied by various researchers using numerous techniques such as Rayleigh-Ritz (R-R) method, finite element method and the intuitive formulations (Gupta et al 2009, 2010a; Venkateswara Rao \& Raju 2002). The applicability of the conventional techniques such as Rayleigh-Ritz method (Gupta et al 2010b) for the post-buckling analysis of composite beams poses difficulty in selecting an accurate axial displacement field variation. Recently, Gupta et al (2010b) and Gunda et al (2011) used an approach of the coupled displacement field (CDF) criteria to derive an approximate axial displacement field variation for given lateral displacement field variation of the composite beam. The main endeavour of the present work is to propose an approximate closed-form expressions for evaluating the post-buckling behaviour of composite beams with axially immovable ends using an intuitive formulation.

The intuitive formulation for composite beams uses two parameters to evaluate the postbuckling behaviour namely, the critical buckling load and the axial stretching force developed in the beam. The critical buckling load is directly taken from the ref. Gupta et al (2010b) and the axial stretching force developed in the post-buckled domain is evaluated using an axial governing

Table 1. Boundary conditions (Gupta et al 2010b) considered for the slender composite beams with axial constraints $(u(0)=u(L)=0)$.

\begin{tabular}{ll}
\hline Boundary configuration & Boundary conditions on $w(x)$ \\
\hline H-H & $w(0)=w(L)=0$ \\
C-C & $w(0)=w^{\prime}(0)=w(L)=w^{\prime}(L)=0$ \\
C-H & $w(0)=w^{\prime}(0)=w(L)=0$ \\
H-G1 & $w(0)=0$ \\
H-G2 & $w(0)=w^{\prime}(L)=0$ \\
C-G1 & $w(0)=w^{\prime}(0)=0$ \\
C-G2 & $w(0)=w^{\prime}(0)=w^{\prime}(L)=0$ \\
\hline
\end{tabular}

*Has one rotational rigid body mode 
Table 2. Expression for axial stretching force (Eq. (8) or Eq. (9)) developed in composite beams with different boundary conditions.

\begin{tabular}{lc}
\hline H - H & $N$ \\
C-C & $b\left(\frac{a \pi\left(8 B_{11}+a A_{11} \pi\right)}{4 L^{2}}\right)$ \\
C - H & $b\left(\frac{A_{11} a^{2} \pi^{2}}{4 L^{2}}\right)$ \\
H - G1 & $b\left(\frac{a\left(4.3119 B_{11}+2.9964 a A_{11}\right)}{L^{2}}\right)$ \\
H-G2 & $b\left(\frac{a \pi\left(8 B_{11}+a A_{11} \pi\right)}{4 L^{2}}\right)$ \\
C-G1 & $b\left(\frac{a \pi\left(4 B_{11} \sqrt{2}+a A_{11} \pi\right)}{8 L^{2}}\right)$ \\
C-G2 & $b\left(\frac{a \pi\left(B_{11}(40-28 \sqrt{(2)})+A_{11}(2 a \sqrt{(2) \pi-3 a \pi))}\right.}{8 L^{2}(-17+12 \sqrt{2})}\right)$ \\
\hline
\end{tabular}

equation in two different approaches. The first approach uses only lateral displacement field variation and the second approach uses both the lateral and axial displacement field variations of the composite beam. The following section briefly summarizes the intuitive formulation involved for the composite beams.

\section{Intuitive formulation for post-buckling analysis of composite beams}

The stress resultants $N_{x}$ and $M_{x}$ that represent axial force and bending moment per unit length of the beam width $(b)$ acting at the mid plane of the beam can be expressed as follows

$$
\left\{\begin{array}{l}
N_{x} \\
M_{x}
\end{array}\right\}=\left[\begin{array}{ll}
A_{11} & B_{11} \\
B_{11} & D_{11}
\end{array}\right]\left\{\begin{array}{l}
\epsilon_{x} \\
\psi_{x}
\end{array}\right\} .
$$

Table 3. Expressions of post-buckling $\left(P_{N L}\right)$ loads (Eq. (4)) for composite beams using intuitive formulation.

\begin{tabular}{|c|c|}
\hline & $P_{N L}$ \\
\hline $\mathrm{H}-\mathrm{H}$ & $b\left(\frac{-4 \pi^{2} B_{11}^{2}+4 D_{11} \pi^{2} A_{11}+32 B_{11}{ }^{2}+8 a A_{11} \pi B_{11}+a^{2} A_{11}{ }^{2} \pi^{2}}{4 A_{11} L^{2}}\right)$ \\
\hline $\mathrm{C}-\mathrm{C}$ & $b\left(\frac{\pi^{2}\left(16 D_{11} A_{11}-16 B_{11}^{2}+A_{11}^{2} a^{2}\right)}{4 L^{2} A_{11}}\right)$ \\
\hline $\mathrm{C}-\mathrm{H}$ & $b\left(\frac{-17.06986140 B_{11}^{2}+20.17238779 D_{11} A_{11}+4.311933381 a A_{11} B_{11}+2.996391838 a^{2} A_{11}{ }^{2}}{L^{2} A_{11}}\right)$ \\
\hline H-G1 & $b\left(\frac{-4 \pi^{2} B_{11}^{2}+4 D_{11} \pi^{2} A_{11}+32 B_{11}^{2}+8 a A_{11} \pi B_{11}+a^{2} A_{11}{ }^{2} \pi^{2}}{4 A_{11} L^{2}}\right)$ \\
\hline H-G2 & $b\left(\frac{16 B_{11}^{2}-2 B_{11}^{2} \pi^{2}+2 D_{11} \pi^{2} A_{11}+4 a A_{11} \pi B_{11} \sqrt{2}+a^{2} A_{11}^{2} \pi^{2}}{8 A_{11} L^{2}}\right)$ \\
\hline \multirow{2}{*}{ C-G1 } & $b\left(\underline{\left(B_{11}^{2}\left(-272+192 \sqrt{2}+34 \pi^{2}-24 \pi^{2} \sqrt{2}\right)+A_{11}{ }^{2}\left(2 a^{2} \pi^{2} \sqrt{2}-3 a^{2} \pi^{2}\right)+A_{11} D_{11}\left(-34 \pi^{2}+24 \pi^{2} \sqrt{2}\right)+A_{11} D_{11}(40 a \pi-28 a \sqrt{2})\right)}\right)$ \\
\hline & $B\left(8 A_{l 1} L^{2}(-17+12 \sqrt{2})\right.$ \\
\hline C-G2 & $b\left(\frac{\pi^{2}\left(4 D_{11} A_{11}-4 B_{11}^{2}+A_{11}^{2} a^{2}\right)}{4 L^{2} A_{11}}\right)$ \\
\hline
\end{tabular}



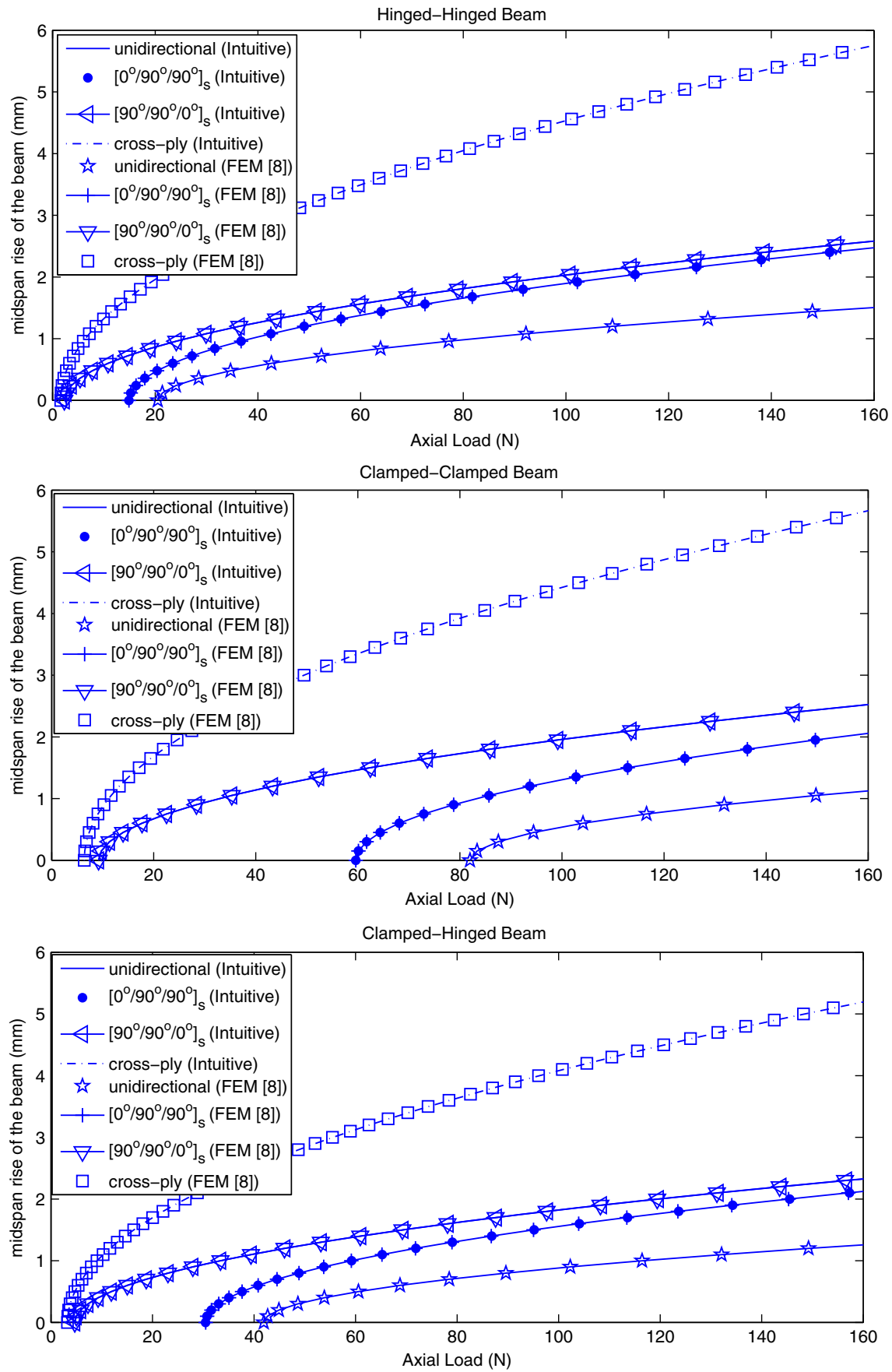

Figure 2. Post-buckling analysis of composite beams with classical boundary conditions-symmetric lay-up schemes. 

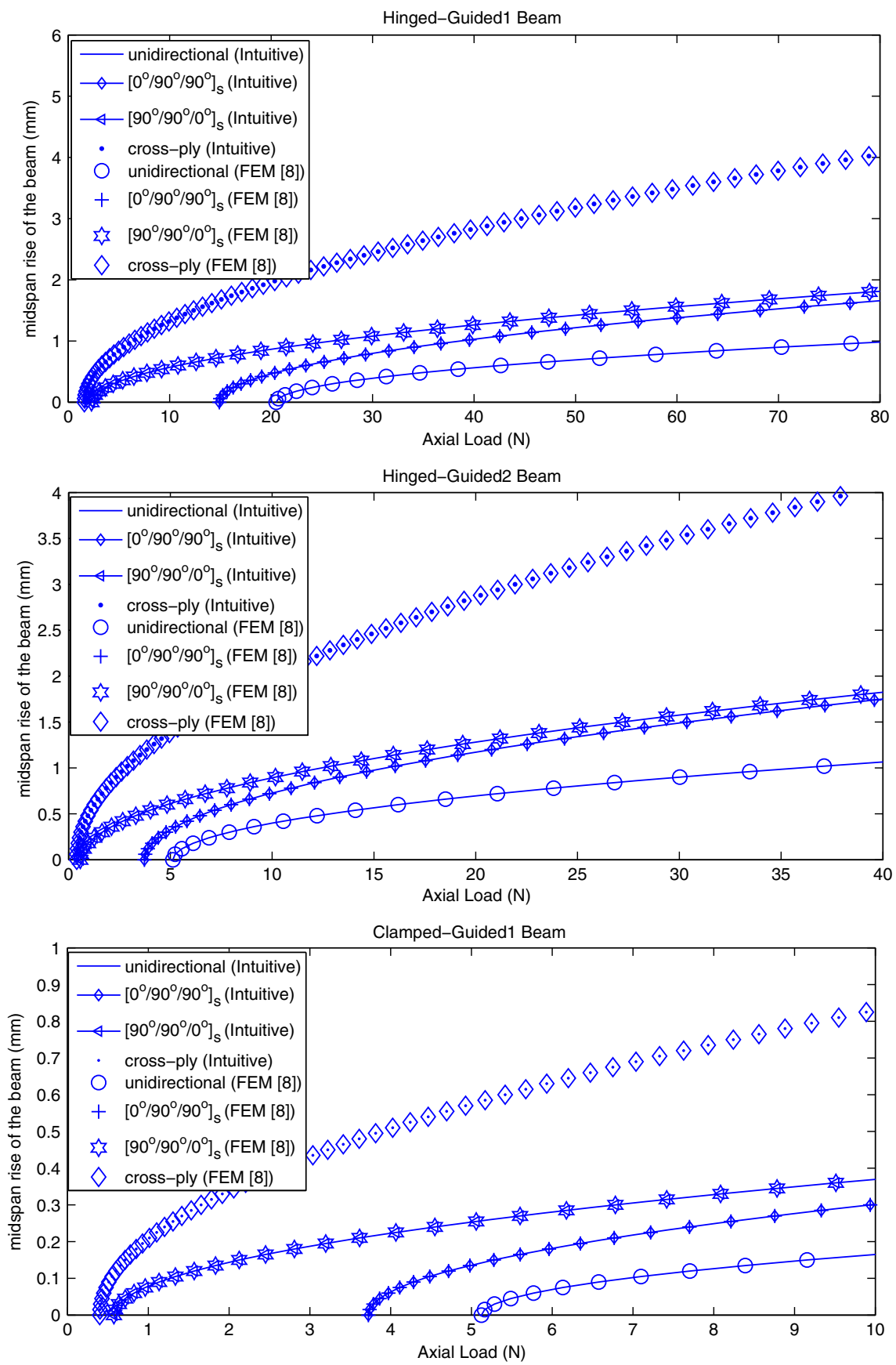

Figure 3. Post-buckling analysis of composite beams with non-classical boundary conditionssymmetric lay-up schemes. 
The geometric nonlinearity of von-Karman type that accounts for the mid-plane stretching is considered in this analysis. The expression for $\epsilon_{x}$ considering von-Karman type of nonlinearity can be expressed as (Gupta et al 2009, 2010b; Reddy 2003, 2004)

$$
\epsilon_{x}=\frac{d u}{d x}+\frac{1}{2}\left(\frac{d w}{d x}\right)^{2}
$$

and $\psi_{x}$ can be expressed as

$$
\psi_{x}=-\frac{d^{2} w}{d x^{2}}
$$

In present formulation, it is assumed that post-buckling load $\left(P_{N L}\right)$ of a composite beam is a summation of critical buckling load $\left(P_{L}\right)$ and axial stretching force $(N)$ developed in the beam due to assumed post-buckled configuration. The same is summarized as below

$$
P_{N L}=P_{L}+N \text {. }
$$

Expression for the net resultant axial stretching force $(N)$ developed in the post-buckled domain of composite beam of length $(L)$ can be expressed as an integrated value using Eq. (1) as follows

$$
N=\frac{b}{L} \int_{0}^{L}\left(A_{11} \epsilon_{x}+B_{11} \psi_{x}\right) d x .
$$

After substitution for $\epsilon_{x}$ and $\psi_{x}$ in to Eq. (5) leads to

$$
N=\frac{b}{L} \int_{0}^{L}\left(A_{11}\left(\frac{d u}{d x}+\frac{1}{2}\left(\frac{d w}{d x}\right)^{2}\right)-B_{11}\left(\frac{d^{2} w}{d x^{2}}\right)\right) d x .
$$

It must be noted that, for axially immovable end conditions of the beam, the net resultant variation in axial displacement field $(\delta u)$ must be zero. The same is expressed as follows

$$
\int_{0}^{L} \delta u=\int_{0}^{L} \frac{\partial u}{\partial x} d x=0
$$

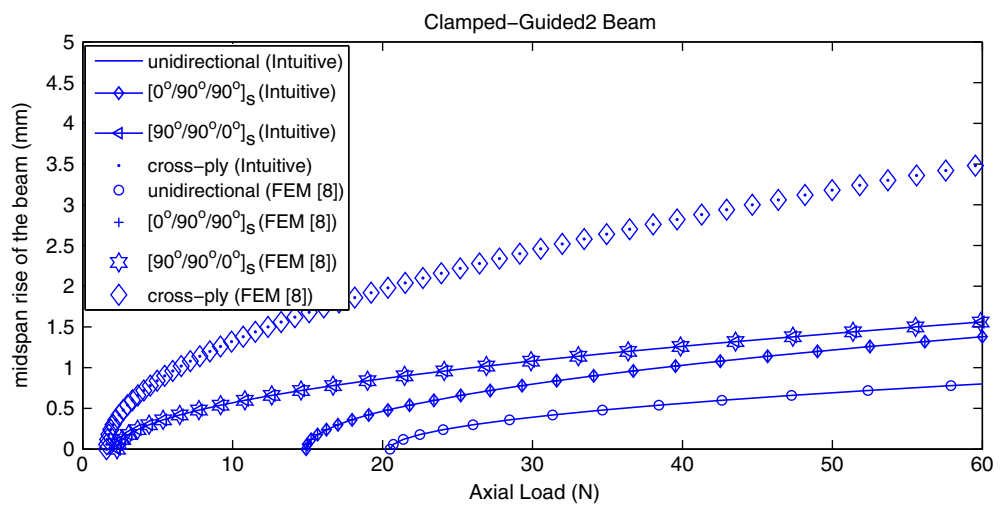

Figure 4. Post-buckling analysis of composite beams with non-classical boundary conditionssymmetric lay-up schemes. 
It can be observed that the axial displacement field $(u)$ variations summarized in ref. Gupta et al (2010b) also satisfy the Eq. (7) for all the beam boundary conditions considered in figure 1.
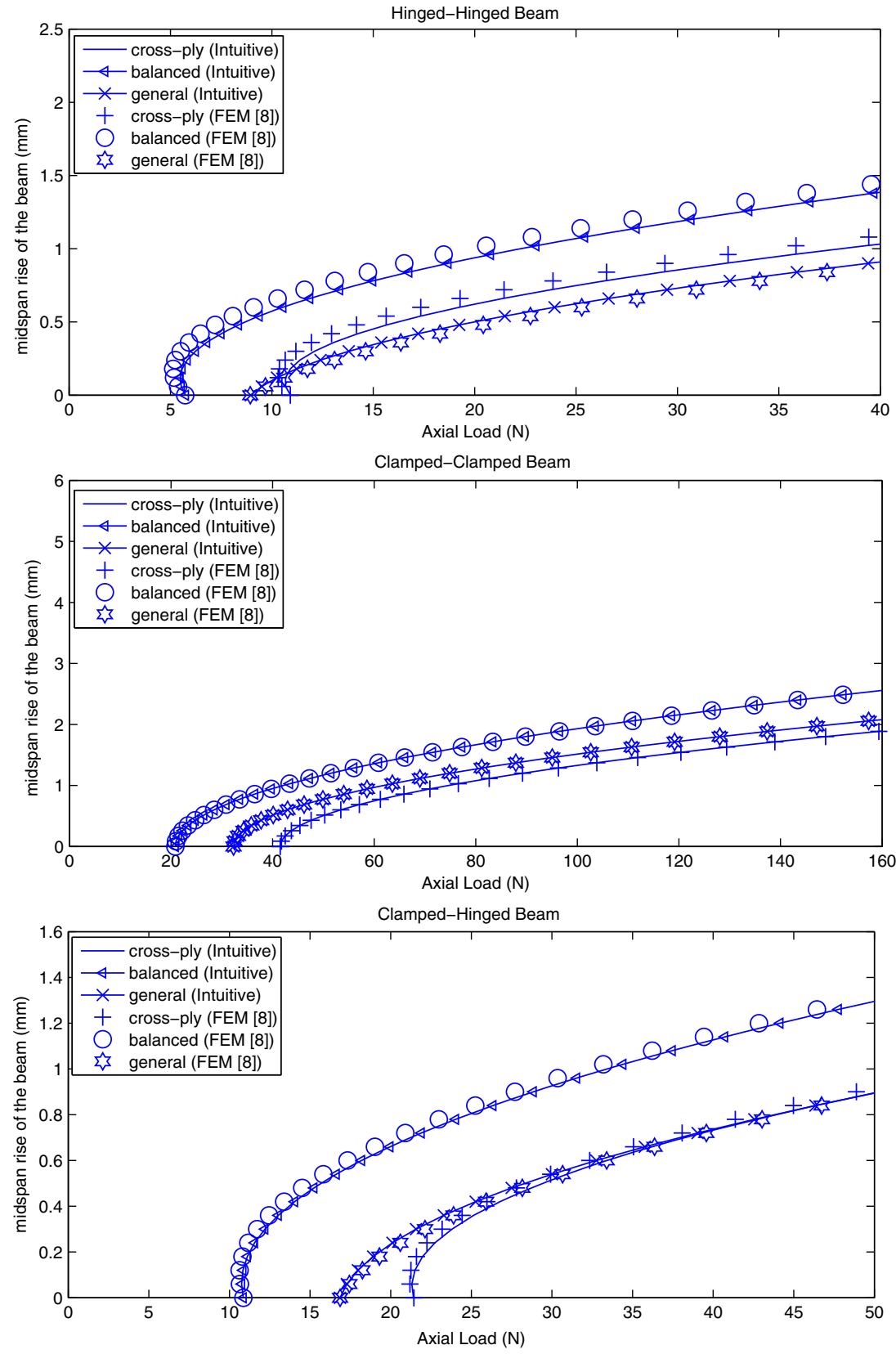

Figure 5. Thermal post-buckling analysis of composite beams with classical boundary conditionsasymmetric lay-up schemes. 
Equation (7) can be used for further simplification of Eq. (6) and the same is expressed as follows

$$
N=\frac{b}{L} \int_{0}^{L}\left(\frac{A_{11}}{2}\left(\frac{d w}{d x}\right)^{2}-B_{11} \frac{d^{2} w}{d x^{2}}\right) d x
$$
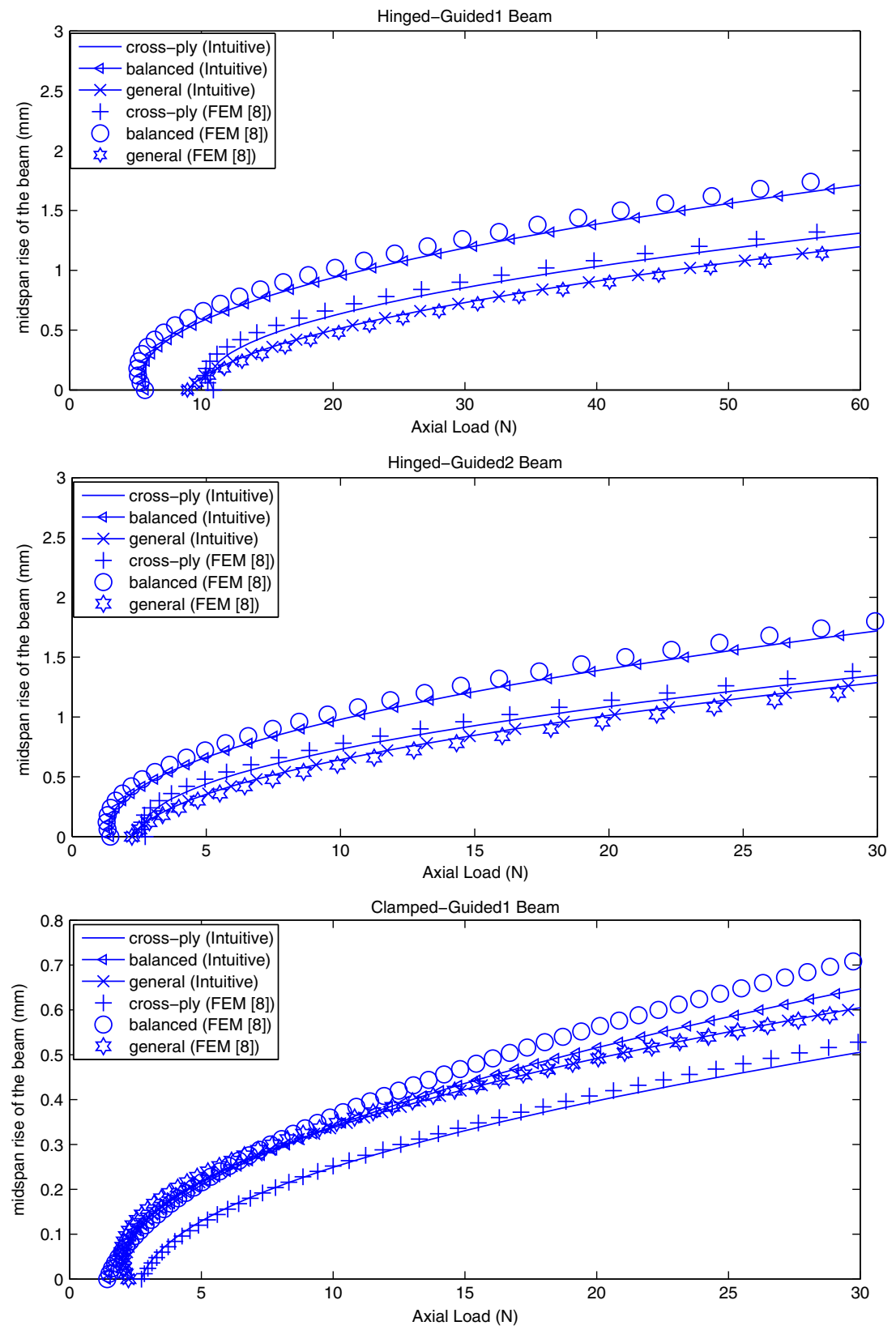

Figure 6. Post-buckling analysis of composite beams with non-classical boundary conditionsasymmetric lay-up schemes. 
Equation (8) represents the net resultant axial stretching force developed in the beam and it is function of only lateral displacement field variation of the beam which in turn alleviates the difficulty of assuming an axial displacement field variation.

Alternatively, the axial stretching force developed at any discrete location $(x)$ of the beam can also be expressed directly using Eq. (1) without integrating across the length of the beam as follows

$$
N=b\left(A_{11}\left(\frac{d u}{d x}+\frac{1}{2}\left(\frac{d w}{d x}\right)^{2}\right)-B_{11}\left(\frac{d^{2} w}{d x^{2}}\right)\right) .
$$

The homogeneous form of axial governing differential equation of a composite beam can be written as $\frac{d N}{d x}=0$, which conveys that $N$ must be constant value across the length of the beam.

The use of Eq. (8) for evaluation of axial stretching force require to assume only the lateral displacement function of the beam, whereas the use of Eq. (9) requires to assume both the lateral and the axial displacement field variations. It can also be observed that Eq. (8) represents an integrated value, whereas the Eq. (9) represents the axial stretching force as function of axial coordinate $(x)$ and it can be evaluated at any discrete location of axial co-ordinate $(x)$. It is observed that either the Eq. (8) or Eq. (9) results in an identical expressions for the axial stretching force developed in the beam, when the displacement field variations from ref. Gupta et al (2010b) are directly used in Eq. (8) or in Eq. (9) for various beam boundary conditions as shown in figure 1.

The expressions for critical buckling loads $\left(P_{L}\right)$ are directly taken from the ref. Gupta et al (2010b) and these are used in the present intuitive formulation. For the sake of brevity, the expressions used for $w, u$ and $P_{L}$ are not presented here and one can refer to Gupta et al (2010b) for more details. Post-buckling behaviour of composite beam with various boundary configurations (table 1) can be evaluated using Eq. (4) based on the expressions obtained for the critical buckling loads $\left(P_{L}\right)$ (from Gupta et al 2010b) and the axial stretching force $(N)$ developed in the post-buckled domain (table 2 can be obtained either from Eq. (8) or Eq. (9)).

Post-buckling load expressions obtained using Eq. (4) are presented in table 3 and these expressions are used for evaluating the post-buckling behaviour of composite beams with symmetric and asymmetric lay-up schemes using an intuitive formulation. It must be noted that table 3 presents a thermal equivalent mechanical loads and equivalent thermal loads (Jones 2006) can be derived by using an appropriate characteristic equation involved for the equivalent mechanical load parameter $\left(P_{N L}\right)$ presented.

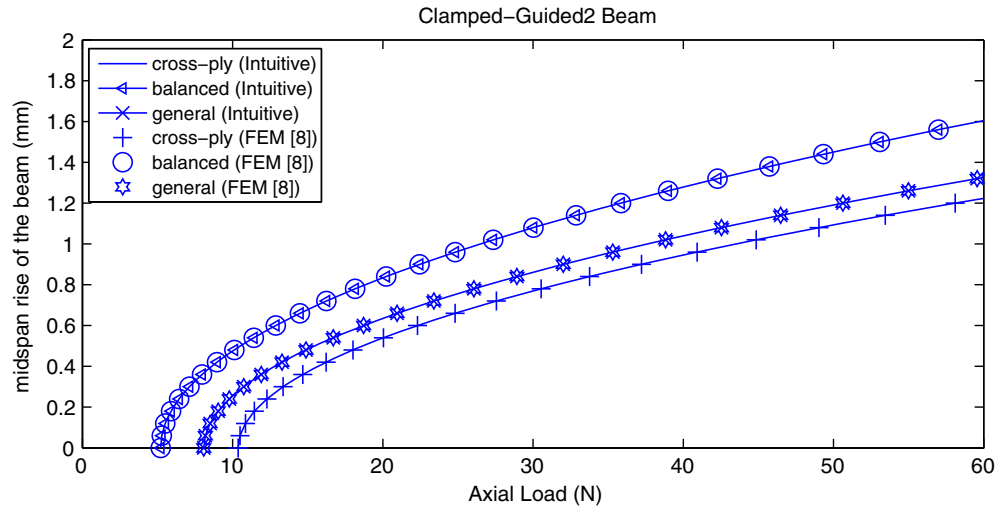

Figure 7. Post-buckling analysis of composite beams with non-classical boundary conditionsasymmetric lay-up schemes. 


\section{Results and discussion}

The present work considers the same example problem which is recently studied by Emam \& Nayfeh $(2009,2010)$ and Gupta et al (2010b). The example problem considers graphite-epoxy
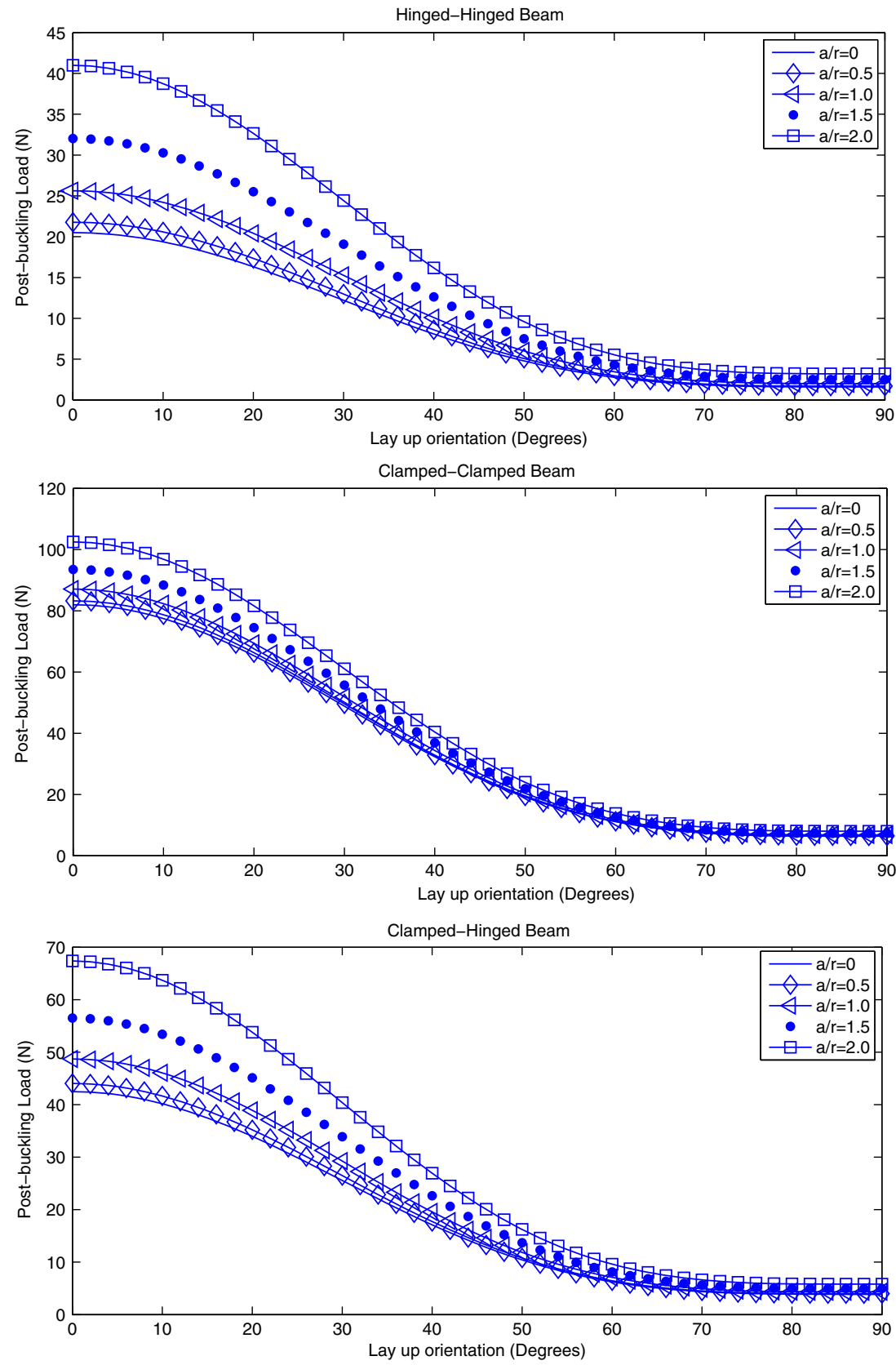

Figure 8. Effect of lay-up orientation on post-buckling analysis of composite beams-unidirectional laminate $\left([\theta]_{6}\right)$. 
laminated beam with six layers of uniform thickness with a length of $0.25 \mathrm{~m}$, a width of $0.01 \mathrm{~m}$, and a height of $0.001 \mathrm{~m}$ (Emam \& Nayfeh 2009, 2010; Gupta et al 2010b). The material properties considered are: $E_{1}=155 \mathrm{GPa}, E_{2}=12.1 \mathrm{GPa}, v_{12}=0.248$ and $G_{12}=4.4 \mathrm{GPa}$. The coupling co-efficients for different symmetric and asymmetric lay-up schemes are discussed in Gupta et al (2010b) and the same lay-up schemes are considered here to demonstrate the accuracy of present intuitive formulation.

The numerical accuracy of closed-form expressions presented in table 3 is demonstrated for symmetric and asymmetric lay-up schemes. Figures 2, 3, 4, 5, 6 and 7 show the comparison of the numerical results of present intuitive formulation with available finite element formulation results (Gupta et al 2010b). It is observed that, the results obtained from the intuitive formulation show good agreement with available finite element formulation results for both the symmetric and asymmetric lay-up schemes of the laminated composite beam. For asymmetric lay-up schemes at higher amplitude ratios, Clamped-Guided1 boundary condition shows slight deviation with FE results of Gupta et al (2010b) and is due to the assumed mode shape used in the study and may be improved by choosing an improved function for the assumed mode shape. The post-buckling load expressions presented in table 3 also reveal the existence of quadratic
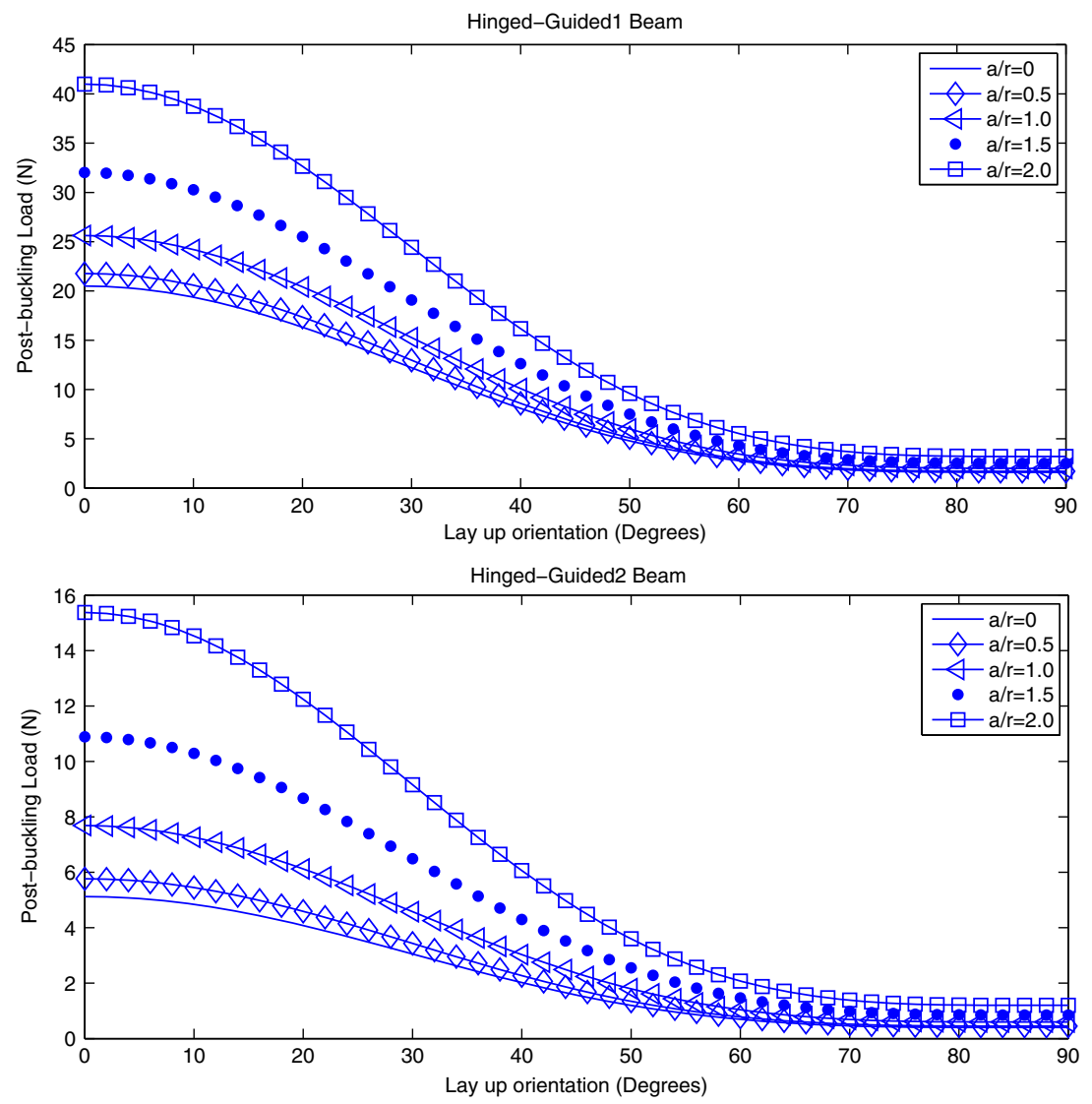

Figure 9. Effect of lay-up orientation on post-buckling analysis of composite beams-unidirectional laminate $\left([\theta]_{6}\right)$. 

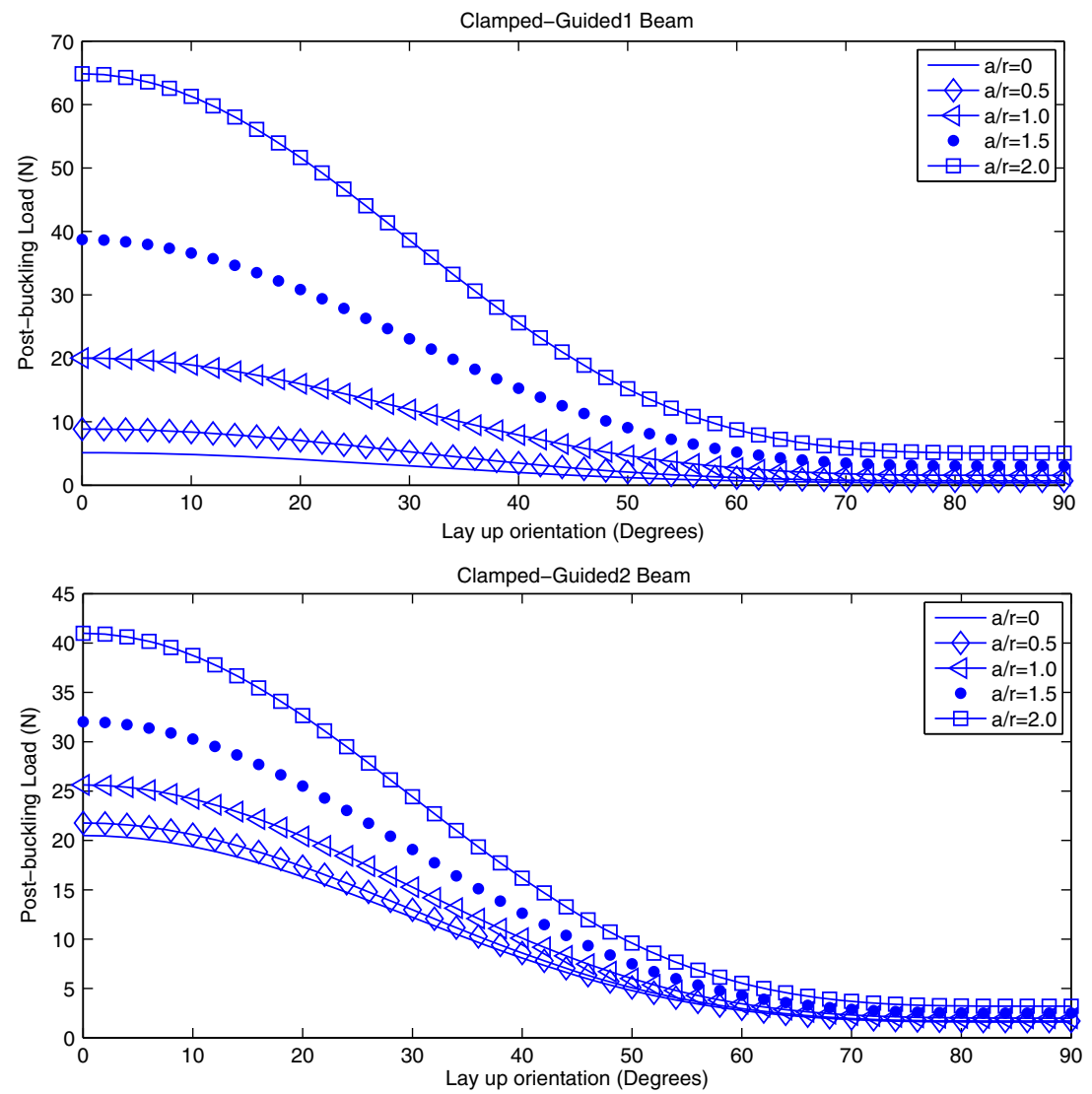

Figure 10. Effect of lay-up orientation on post-buckling analysis of composite beams-unidirectional laminate $\left([\theta]_{6}\right)$.

nonlinearity for few beam boundary conditions as it is already stated in the study presented by Gupta et al (2010b).

A unidirectional laminate $[\theta]_{6}$ with six laminae is considered for studying the effect of layup orientation. The effect of lay-up orientation $(\theta)$ on post-buckling behaviour is investigated using the closed-form expressions presented in table 3 and the corresponding results are shown in figures 8, 9 and 10 for various beam boundary conditions. It is observed that lay-up orientation $(\theta)$ and central amplitude ratio of the beam significantly influences the variation of post-buckling load. The present study demonstrates the wider applicability of the intuitive formulation to the post-buckling analysis of composite beams with general boundary conditions. The confidence gained from this study can be utilized for evaluating the post-buckling behaviour of complex structural elements such as plates and shells.

\section{Conclusion}

The present study investigates the post-buckling behaviour of composite beams with axially immovable ends using an intuitive formulation. Intuitive formulation uses two parameters; 
namely, the critical buckling load and the axial stretching force developed in the composite beam. The accuracy of the simple closed-form expressions obtained from the intuitive formulation is demonstrated for various lay-up schemes, which clearly shows the simplicity and robustness of the proposed approach in getting reasonably realistic solutions to the complex engineering problems of post-buckling analysis.

\section{References}

Carlos E N M 2009 Buckling and post-buckling of extensible rods revisited: A multiple-scale solution. Int. J. Nonlinear Mech. 44(2): 200-208

Emam S A 2011 Analysis of shear-deformable composite beams in post-buckling. Composite Struct. 94(1): 24-30

Emam S A and Nayfeh A H 2009 Post-buckling and free vibrations of composite beams. Composite Struct. 88: 636-642

Emam S A and Nayfeh A H 2010 Corrigendum to post-buckling and free vibrations of composite beams. Composite Struct. 92: 2608

Gunda J B, Gupta R K, Ranga Janardhan G and Venkateswara Rao G 2011 Large amplitude vibration analysis of composite beams: simple closed-form solutions. Composite Struct. 93(2): 870-879

Gupta R K, Gunda, J B, Ranga Janardhan G and Venkateswara Rao G 2009 Comparative study of thermal postbuckling analysis of uniform slender and shear flexible columns using rigorous finite element and intuitive formulations. Int. J. Mech. Sci. 51: 204-212

Gupta R K, Gunda J B, Ranga Janardhan G and Venkateswara Rao G 2010a Thermal post-buckling analysis of slender columns using the concept of coupled displacement field. Int. J. Mech. Sci. 52(4): 590-594

Gupta R K, Gunda J B, Ranga Janardhan G and Venkateswara Rao G 2010b Post-buckling analysis of composite beams: Simple and accurate closed-form expressions. Composite Struct. 92(8): 1947-1957

Huang H and Han Q 2009 Nonlinear buckling and postbuckling of heated functionally graded cylindrical shells under combined axial compression and radial pressure. Int. J. Nonlinear Mech. 44(2): 209-218

Iyengar N G R 1988 Structural stability of columns and plates. Chichester: E Horwood Publications

Jones R M 2006 Buckling of bars, plates and shells. Virginia: Bull Ridge Publishing, Blacksburg

Li S R and Zhou Y H 2005 Post-buckling of a hinged-fixed beam under uniformly distributed follower forces. Mech. Res. Commun. 32: 359-367

Nayfeh A H and Emam S A 2008 Exact solutions and stability of the postbuckling configurations of beams. Nonlinear Dynamics 54(4): 395-408

Niels O and Alexander P S 2008 Bifurcation and post-buckling analysis of bimodal optimum columns. Int. J. Solids Struct. 45(14-15): 3967-3995

Razakamiadana A and Zidi M 1999 Buckling and post-buckling of concentric cylindrical tubes under external pressure. Mech. Res. Commun. 26(3): 353-362

Reddy J N 2003 Mechanics of laminated composite plates and shells: theory and analysis. 2nd edition, Boca Raton: CRC Press

Reddy J N 2004 An introduction to nonlinear finite element analysis. Oxford (UK): Oxford University Press

Sebastian P M 2008 Nonlinear buckling and postbuckling behaviour of thin-walled beams considering shear deformation. Int. J. Nonlinear Mech. 43(5): 345-365

Vaz M A and Patel M H 2007 Post-buckling behaviour of slender structures with a bi-linear bending moment curvature relationship. Int. J. Nonlinear Mech. 42(3): 470-483

Venkateswara Rao G and Raju K K 1984 Thermal post buckling of columns. AIAA Journal 22(6): 850-851

Venkateswara Rao G and Raju K K 2002 Thermal post-buckling of uniform columns: A simple intuitive method. AIAA Journal 40(10): 2138-2140 